\title{
The Adult Substantia Nigra Contains Progenitor Cells with Neurogenic Potential
}

\author{
D. Chichung Lie, ${ }^{1}$ Gustavo Dziewczapolski, ${ }^{2}$ Andrew R. Willhoite, ${ }^{1}$ Brian K. Kaspar, ${ }^{1}$ Clifford W. Shults, ${ }^{2}$ and \\ Fred H. Gage ${ }^{1}$
}

1 Laboratory of Genetics, The Salk Institute for Biological Studies, La Jolla, California 92037, and 2Department of

Neurosciences, University of California San Diego/Veterans Affairs Medical Center, La Jolla, California 92161

In Parkinson's disease, progressive loss of dopaminergic neurons in the substantia nigra pars compacta (SN) leads to debilitating motor dysfunction. One current therapy aims at exogenous cellular replacement of dopaminergic function by transplanting fetal midbrain cells into the striatum, the main projection area of the SN. However, results using this approach have shown variable success. It has been proposed that cellular replacement by endogenous stem/progenitor cells may be useful for therapeutic interventions in neurodegenerative diseases, including Parkinson's disease. Although it is widely accepted that progenitor cells are present in different areas of the adult CNS, it is unclear whether such cells reside in the adult SN and whether they have the potential to replace degenerating neurons. Here, we describe a population of actively dividing progenitor cells in the adult SN, which in situ give rise to new mature glial cells but not to neurons. However, after removal from the $\mathrm{SN}$, these progenitor cells immediately have the potential to differentiate into neurons. Transplantation of freshly isolated SN progenitor cells into the adult hippocampus showed that these cells also have a neuronal potential under in vivo conditions. These results suggest that progenitor cells reside in the adult $\mathrm{SN}$ and can give rise to new neurons when exposed to appropriate environmental signals. This developmental potential of SN progenitor cells might be useful for future endogenous cell replacement strategies in Parkinson's disease.

Key words: Parkinson's disease; neural progenitor cells; cell replacement; gliogenesis; transplantation; substantia nigra
The dopaminergic neurons in the substantia nigra pars compacta (SN) are important regulators of corticostriatal neurotransmission. In Parkinson's disease (PD), progressive loss of these neurons leads to debilitating motor dysfunction. Current treatment consists primarily of pharmacological dopamine replacement for amelioration of motor deficits (Olanow et al., 2001). Based on previous animal studies, experimental therapies have sought to restore dopaminergic neurotransmission by exogenous cell replacement, which is achieved by transplanting fetal dopaminergic neurons into the striatum, the main target area of the SN (Olanow et al., 1996; Lindvall and Hagell, 2000; Freed et al., 2001). However, the clinical success of transplantation strategies has been hampered by major problems such as availability of cells, paucity of dopaminergic neurons in grafts, immunological response after transplantation, probable failure of cells to integrate into the host circuit, and the low percentage of survival of grafted cells (Bjorklund and Lindvall, 2000; Dunnett et al., 2001).

The regenerative capacity of the adult CNS is limited and has been considered to be confined to postmitotic events. However, there is growing evidence that new mature neural cells are gen-

\footnotetext{
Received Feb. 7, 2002; revised April 22, 2002; accepted May 21, 2002.

D.C.L. was supported in part by the Deutsche Forschungsgemeinschaft. G.D. is supported by Consejo Nacional de Investigaciones Científicas y Técnicas and Fundación Antorchas. B.K.K. is supported by the Pasarow Foundation. F.H.G. is supported by National Institute of Health Grant AG08514, the Lookout Fund, the Fox Foundation, and the National Parkinson Foundation. We thank Dr. S. Colamarino, Dr. H. Song, Dr. R. Summers, and M. L. Gage for helpf ul critique of this manuscript and L. Kitabayashi, S. Forbes, and A. Dearie for excellent technical assistance.

Correspondence should be addressed to Dr. F. H. Gage, Laboratory of Genetics, The Salk Institute for Biological Studies, 10010 North Torrey Pines Road, La Jolla, CA 92037. E-mail: gage@salk.edu.

Copyright (C) 2002 Society for Neuroscience $\quad 0270-6474 / 02 / 226639-11 \$ 15.00 / 0$
}

erated throughout adulthood, suggesting that the adult CNS retains the ability for endogenous cell replacement. These cells are derived from actively dividing progenitor cells, which display a broad or restricted differentiation pattern depending on their site of residence. The generation of mature cells of all neural lineages, including neurons, has been consistently demonstrated in only two distinct areas of the forebrain (i.e., the hippocampus and the subventricular zone) (Altman and Das, 1965; Bayer, 1982; Kaplan and Bell, 1984; Levison and Goldman, 1993; Lois and Alvarez-Buylla, 1993; Luskin, 1993; Kuhn et al., 1996). In contrast, in the adult spinal cord progenitor cells give rise to glial cells only (Horner et al., 2000). However, the in vivo differentiation pattern may not reflect the entire lineage potential of resident progenitor cells, because regional environmental cues appear to restrict in situ differentiation to distinct neural lineages. For example, in vitro analysis and transplantation studies have suggested that adult progenitor cells from the spinal cord have the potential to give rise to cells of all neural lineages (Weiss et al., 1996; Shihabuddin et al., 1997, 2000). In addition, isolated cortical progenitor cells have the potential to give rise to glia and neurons in vitro (Palmer et al., 1999), and limited de novo neurogenesis from progenitor cells has been observed in the adult mammalian neocortex after chromophore-induced apoptotic lesion (Magavi et al., 2000), which suggests that cortical progenitors in fact have a broader differentiation potential than observed under normal conditions.

To date, it is unclear whether cells with the potential to give rise to new neural cells exist in the adult $\mathrm{SN}$ and whether active cell replacement occurs in this CNS region. Here, we investigate the presence of progenitor cells in the adult $\mathrm{SN}$, their in vivo differentiation pattern, and their lineage potential. Our results 
indicate that cells with a broad differentiation potential, which includes neurons, astrocytes, and oligodendrocytes, are present in the adult $\mathrm{SN}$.

\section{MATERIALS AND METHODS}

Animals. For all experiments, young adult female Fisher 344 rats (8-9 weeks of age; Harlan Sprague Dawley, Indianapolis, IN) were used. Animals were housed in standard cages and had ad libitum access to food and water.

Green fluorescent protein-retrovirus injections. Five animals were deeply anesthetized and injected stereotactically with $2 \mu \mathrm{l}$ of high-titer NITgreen fluorescent protein $(\mathrm{GFP})$ retrovirus $\left(5 \times 10^{5} \mathrm{IU} / \mu \mathrm{l}\right)$ (generously provided by H. van Praag, Salk Institute, La Jolla, CA) (Palmer et al., 1999) into the left SN [anteroposterior (AP), -5.4; mediolateral (ML), -2.2 ; dorsoventral (DV), -7.7 from bregma; nose piece, -3.3$]$. Animals were anesthetized and perfused intracardially with $4 \%$ paraformaldehyde in $100 \mathrm{~mm}$ phosphate buffer, $\mathrm{pH} 7.4,36 \mathrm{hr}$ later.

Bromodeoxyuridine injections. For birthdating studies, eight animals received a single intraperitoneal injection of bromodeoxyuridine (BrdU) (50 mg/kg; Sigma, St. Louis, MO). Animals were perfused at $2 \mathrm{hr}$ or $3 \mathrm{~d}$ after injection. For phenotype and fate studies, 20 animals received intraperitoneal injections of $\operatorname{BrdU}(200 \mathrm{mg} / \mathrm{kg})$ each day for $10 \mathrm{~d}$. At $1 \mathrm{~d}$ after injection, one-half of the animals $(n=10)$ were perfused. The remaining animals $(n=10)$ were perfused at 4 weeks after injection.

6-Hydroxydopamine lesions. Twelve animals were injected stereotactically with two deposits of $1.5 \mu \mathrm{l}$ of 6-hydroxydopamine (6-OHDA) (Sigma) $(4 \mu \mathrm{g} / \mu \mathrm{l}$ in $0.9 \% \mathrm{NaCl}$ supplemented with $0.02 \%$ ascorbic acid) into the left medial forebrain bundle (AP, $-3.8 ; \mathrm{ML},-1.5 ; \mathrm{DV},-7.3$ and -7.1 from bregma; nose piece, -3.3 ). Twelve animals received injections of vehicle. One day after injury, animals received intraperitoneal BrdU injections $(200 \mathrm{mg} / \mathrm{kg}$ ) each day for 12 consecutive days. Animals were perfused 4 weeks after the last BrdU injection.

Isolation and culturing of adult progenitors. Adult progenitor cells were isolated as described previously (Palmer et al., 1999). The SN was dissected using a dissection microscope. Contamination by ependymal and subependymal cells was avoided by complete removal of tissue adjacent to the ventricle. The pial surfaces were trimmed from the tissue to remove the meninges. Tissues were digested in papain $(2.5 \mathrm{U} / \mathrm{ml}$; Worthington, Freehold, NJ), DNase (250 U/ml; Worthington) and neutral protease $(1 \mathrm{U} / \mathrm{ml}$ Dispase; Boehringer Mannheim, Indianapolis, IN) dissolved in HBSS. Whole digested tissue was washed and suspended in DMEM-10\% fetal bovine serum (FBS) (Hyclone, Logan, UT). An equal volume of Percoll solution consisting of nine parts of Percoll (Amersham Pharmacia Biotech, Uppsala, Sweden) and one part of $10 \times$ PBS (Irvine Scientific, Santa Ana, CA) was added. The cell suspension was centrifuged for $30 \mathrm{~min}, 18^{\circ} \mathrm{C}$, at $20,000 \times g$. Cells from the low-buoyancy fraction were harvested, rinsed in PBS, and plated onto Porn/Lamcoated tissue culture dishes (Fisher Scientific, Houston, TX) in DMEM$10 \%$ FBS. The medium was replaced after $16 \mathrm{hr}$ with serum-free growth medium consisting of DMEM/F-12 (1:1) supplemented with N2 supplement (Life Technologies, Gaithersburg, MD). Growth factors were added at the following concentrations: human FGF2 (Peprotech, Rocky Hill, NJ), 20 ng/ml; mouse FGF8b (R \& D Systems, Minneapolis, MN), $40 \mathrm{ng} / \mathrm{ml}$. To promote differentiation, growth medium was replaced with DMEM/F-12 containing $1 \%$ FBS and $0.5 \mu \mathrm{m}$ of all-trans retinoic acid. For immediate differentiation experiments, two additional differentiation paradigms were applied: 1\% FBS and $5 \mu \mathrm{m}$ of forskolin (Palmer et al., 1997) or astrocyte feeder layer in serum-free defined medium (Song et al., 2002).

Clonal analysis. Progenitors were cultured for $7 \mathrm{~d}$ in growth medium, harvested with trypsin-EDTA solution, washed one time with DMEM/ F-12, and suspended to a final concentration of $10^{6}$ cells $/ \mathrm{ml}$ in growth medium supplemented with $2 \mu \mathrm{g} / \mathrm{ml}$ polybrene. Volumes of NIT-GFP retrovirus sufficient to infect $\sim 10-20$ cells were added to $0.2 \mathrm{ml}$ of cells and then incubated for $30 \mathrm{~min}$ at $37^{\circ} \mathrm{C}$. The cells were pelleted, resuspended in growth medium, and plated into $6 \mathrm{~cm}$ tissue culture dishes. One day later, the locations of individual green cells were marked. Adjacent clones closer than $1 \mathrm{~cm}$ apart were excluded from the study. Cells were grown in growth medium for $7 \mathrm{~d}$ and then switched to differentiation medium for another $7 \mathrm{~d}$. Cells were fixed for $20 \mathrm{~min}$ with $4 \%$ paraformaldehyde.

Immunofluorescent staining. Floating tissue sections or cells were rinsed with Tris-buffered saline (TBS) and then blocked for $30 \mathrm{~min}$ at room temperature in TBS containing $0.3 \%$ Triton $\mathrm{X}-100$ and $5 \%$ preim- mune donkey serum $(\mathrm{TBS}++)$. Samples were incubated in $\mathrm{TBS}++$ containing dilutions of primary antibodies for $24-72 \mathrm{hr}$ at $4^{\circ} \mathrm{C}$. Samples were washed three times with TBS for $10 \mathrm{~min}$ at room temperature and blocked in TBS ++ for $1 \mathrm{hr}$. Samples were then incubated for $2 \mathrm{hr}$ with secondary antibodies conjugated to aminomethyl coumarin, fluorescein isothiocyanate, Texas Red, or cyanin 5. Secondary antibodies (donkey; Jackson ImmunoResearch, West Grove, PA) were used at a final dilution of 1:250 in TBS ++ . Samples were washed three times with TBS, treated with $10 \mathrm{mg} / \mathrm{ml} \mathrm{4'}$,6'-diamidino-2-phenylindole (DAPI) (Sigma) for 10 min, and coverslipped in $20 \%$ polyvinylalcohol (20,000-30,000 molecular weight; Air Products and Chemicals, Allentown, PA) in 50\% glycerol (w/v) containing 2.5\% w/v 1,4-diazobicyclo-[2.2.2]-octane (Sigma).

For BrdU staining, samples were pretreated with $50 \%$ formamide in $2 \times \mathrm{SSC}$ for $2 \mathrm{hr}$ at $65^{\circ} \mathrm{C}$, followed by $15 \mathrm{~min}$ in $2 \times \mathrm{SSC}, 30 \mathrm{~min}$ in $2 \mathrm{~N} \mathrm{HCl}$ at $37^{\circ} \mathrm{C}, 10 \mathrm{~min}$ in $0.1 \mathrm{M}$ borate buffer, and six $15 \mathrm{~min}$ rinses in $\mathrm{TBS}, \mathrm{pH}$ 7.5 .

Primary antibodies generated in mice, rats, rabbits, and guinea pigs were used at the following concentrations: mouse anti-TuJ1 (1:50008000; Promega, Madison, WI), rabbit anti-TuJ1 (1:1000-4000; Covance, Richmond, CA), mouse anti-Map 2ab (1:250; Sigma), mouse antineuronal nuclear antigen $(\mathrm{NeuN})(1: 10$; hybridoma supernatant kindly provided by R. Mullen, University of Utah, Salt Lake City, UT), mouse anti-receptor-interacting protein (RIP) (1:20; Developmental Studies Hybridoma Bank, University of Iowa, Iowa City, IA), rabbit anti-NG2 chondroitin sulfate proteoglycan (NG2) (1:500; Chemicon, Temecula, CA), mouse anti-adenomatous polyposis coli tumor suppressor gene (APC) (1:100; Chemicon), rabbit anti-S100 $\beta$ (1:5000; Swant, Bellinzona, Switzerland), guinea pig anti-GFAP (1:500; Advanced Immunochemical, Inc., Long Beach, CA), mouse anti-A2B5 (1:100; Boehringer Mannheim), rat anti-BrdU (1:250; Accurate Chemicals, Westbury, NY), mouse anti-Ox42 (1:1000; Chemicon), mouse anti-nestin (1:250; PharMingen, San Diego, CA), rabbit anti-tyrosine-hydroxylase (TH) (1:500; Protos Biotech, Burlingame, CA), and mouse anti-TH (1:250; Roche, Indianapolis, IN). Fluorescent samples were evaluated using a Bio-Rad (Hercules, CA) MRC1024UV confocal imaging system.

Quantification of newly generated cells. Estimation of the number of BrdU-positive cells located within the adult SN was achieved by using the optical fractionator sampling design and formula (West, 1999) with the assistance of a stereology system (Stereo Investigator version 2001 4.33a; MicroBrightField, Inc., Colchester, VT). Every sixth $40 \mu \mathrm{m}$ coronal section of the midbrain was evaluated after double-immunostaining for $\mathrm{TH}$ and BrdU. With the aid of a Stereo Investigator software-controlled stage attached to an Olympus (Melville, NY) BH-2 fluorescence microscope and Dage (Michigan City, IN) MTI CCD-300TIFG video camera, the SN was delineated using the TH immunostaining as guide. Counts were made using an unbiased counting frame superimposed on the image of the SN viewed under a $20 \times$ objective (sampling frame area, 10,000 $\mu \mathrm{m}^{2}$; sampling frame height, $26 \mu \mathrm{m}$; top and bottom guard zones, at least $3 \mu \mathrm{m}$; sampling intervals, $x=240 \mu \mathrm{m}, y=150 \mu \mathrm{m} ;)$.

Phenotypic analysis. To determine the phenotype of proliferating cells and their progeny in the SN, 100 randomly selected, BrdU-positive cells per animal in this region were evaluated for colabeling with each phenotypic marker. For each BrdU-positive cell, the complete cell nucleus was followed through the $z$-axis, and only cells with a well circumscribed, immunopositive cell body or nucleus were considered positive for a particular phenotype.

The labeling index was calculated by dividing the number of cells that were double labeled for BrdU and a phenotypic marker by the number of evaluated BrdU-positive cells.

To determine the phenotype of cultured progenitor cells, 1000 cells per condition observed in nonoverlapping fields of view were evaluated for the expression of phenotypic markers. Labeling indices were calculated by dividing the number of positive cells by the total number of cells.

Transplantation. To enable the detection of transplanted cells in vivo, BrdU $(5 \mu \mathrm{M})$ was added to the culture medium at day 4 in vitro. Cells were harvested $48 \mathrm{hr}$ later by trypsinization, washed once with $0.1 \mathrm{M} \mathrm{PBS}$, collected by centrifugation at $2500 \mathrm{rpm}$ for $3 \mathrm{~min}$, and resuspended in 0.1 M PBS at a concentration of 100,000 cells/ $\mu$ l. One microliter of cell suspension was stereotactically injected into the hippocampus (AP, - 4; $\mathrm{ML}, \pm 2 ; \mathrm{DV},-3.5$ from bregma; nose piece, -3.3$)(n=8)$ or the SN $(n=8)$ of adult female Fischer 344 rats. At 3 weeks after transplantation, animals were perfused. To determine the frequency at which BrdUpositive cells demonstrated a particular phenotype in the dentate gyrus or the SN, BrdU-immunoreactive transplanted cells (100 randomly selected BrdU-positive cells/animal) in this region were examined for 

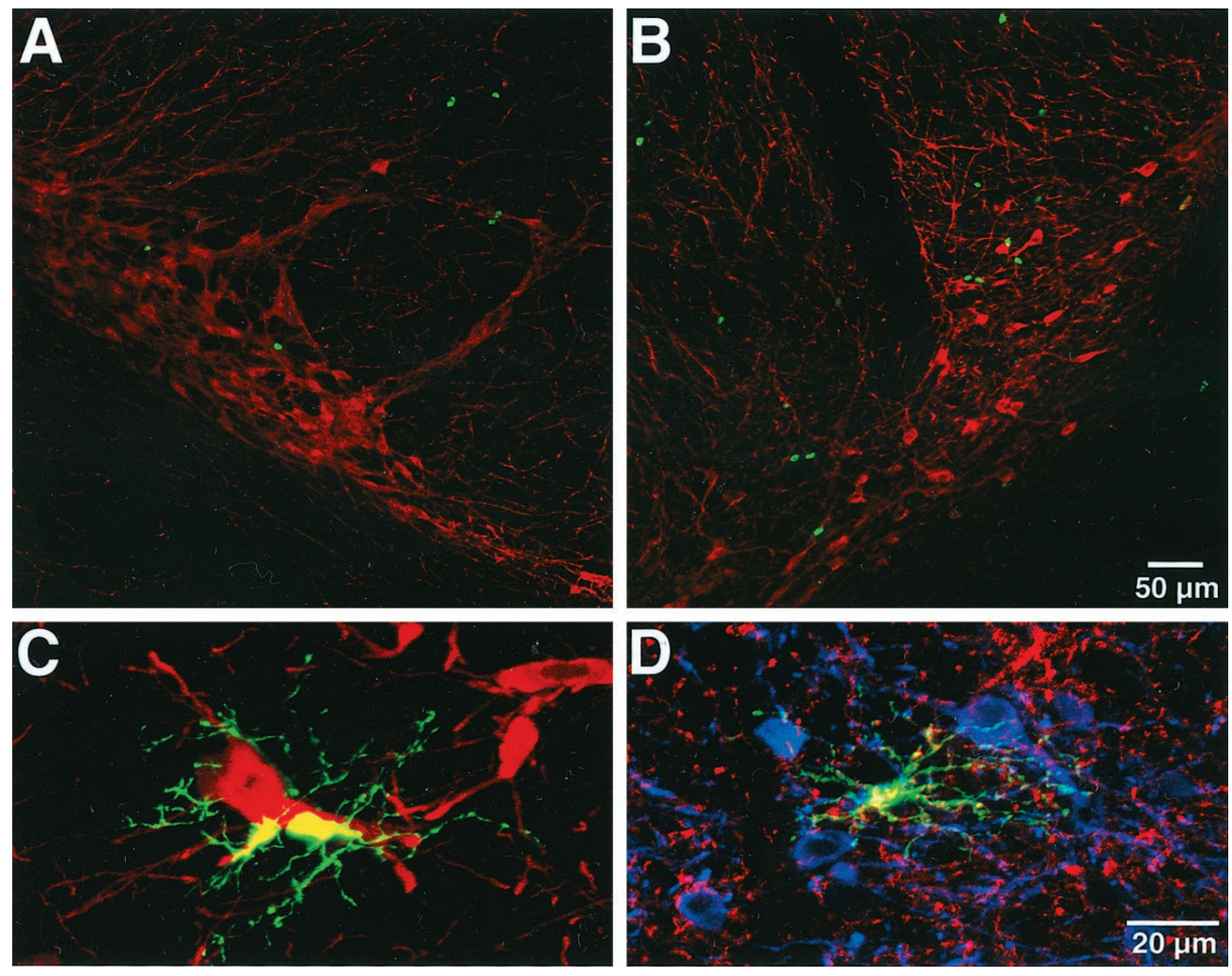

Figure 1. Proliferating cells are present in the adult SN. $A$, BrdU-labeled cells (green) are detected $2 \mathrm{hr}$ after injection. $B$, At $3 \mathrm{~d}$ after injection, more BrdUpositive cells ( green) are present in the SN. Cells are mostly found in doublets. $A, B$, TH in red. $C, D$, Proliferating cells are also detected by injection of a GFP retrovirus into the SN. $D$, Some of the infected cells express NG2 (red, colabeling with GFP in yellow). TH in red $(C)$ or blue $(D)$.

colocalization with lineage-specific markers. The number of transplanted cells that differentiated into a particular phenotype was expressed as a percentage of the BrdU-positive cells examined.

\section{RESULTS}

\section{Cell genesis in the adult SN}

To determine whether the adult midbrain contains dividing cells, animals were pulsed with a single dose of BrdU and killed $2 \mathrm{hr}$ or $3 \mathrm{~d}$ later. At $2 \mathrm{hr}$ after injection, cells undergoing DNA replication had incorporated the label but had not had time to migrate far from the site of incorporation. At this time point, BrdU-positive cells were detected throughout the entire midbrain including the $\mathrm{SN}$, indicating that proliferating cells are present in this region (Fig. 1a). At $3 \mathrm{~d}$ after injection, the number of BrdU-labeled cells in the SN appeared to have increased, and cells were found predominantly in doublets, suggesting that cells had divided locally (Fig. 1b). The presence of locally dividing cells in the adult $\mathrm{SN}$ was confirmed by stereotactic injection of a Moloney murine leukemia virus (MoMLV)-based GFP retrovirus into the SN. MoMLV-based retroviruses infect only dividing cells. At $36 \mathrm{hr}$ after injection, GFP-positive cells were detected in the SN. These cells had small round cell bodies and elaborate processes (Fig. 1c) and were in some cases colabeled for NG2, an early glial progenitor cell marker (Fig. 1d).

\section{Phenotypic analysis of newborn cells in the adult SN}

To determine the phenotype and the fate of dividing cells, animals were injected daily with BrdU for $10 \mathrm{~d}$ and perfused at $1 \mathrm{~d}$ and 4 weeks after injection. Stereological analysis showed that the number of BrdU-positive cells did not differ significantly between those time points $[2761 \pm 381$ (average \pm SEM) at $1 \mathrm{~d}$ after injection and $2943 \pm 505$ at 4 weeks after injection], suggesting that a significant proportion of dividing cells or their progeny was maintained during this period. The relative contribution of pro- liferation, survival, and cell death to the maintenance of newly generated cells was not assessed in this study. Sections were stained with glia- and neuron-associated markers. One-half of the BrdU-positive cells in the SN colabeled with the potential glial progenitor marker NG2 at $1 \mathrm{~d}$ after injection (49.6 $\pm 3 \%$ ) (Fig. $2 a)$. At 4 weeks after injection, the percentage of NG2-labeled, BrdU-positive cells had decreased only slightly $(42.6 \pm 1.1 \%)$, suggesting that many cells remained as glial progenitor cells in the SN. At $1 \mathrm{~d}$ after injection but not at 4 weeks after injection, a small population of BrdU-positive cells $(\sim 0.1 \%)$ stained for the intermediate filament nestin (Fig. $2 b$ ), which is expressed by multipotent neural progenitor cells during development (Lendahl et al., 1990). These BrdU/nestin-positive cells were not associated with blood vessels, indicating that these cells were neural progenitor cells and not endothelial cells, which have been described to express nestin in the adult CNS (Kobayashi et al., 1998; Palmer et al., 2000). Few newborn cells $(<0.1 \%)$ expressed mature glial markers $(\mathrm{S} 100 \beta)$ at the early time point. In contrast, at 4 weeks after injection, $14 \%$ of BrdU-labeled cells had differentiated into oligodendrocytes $(\mathrm{APC}+/ \mathrm{GFAP}-)(12.9 \pm 0.7 \%)$ or astrocytes $(\mathrm{S} 100 \beta+)(1.4 \pm 0.2 \%)$ (Fig. $3 a, b)$. Very few BrdU-positive cells $(<0.1 \%)$ expressed $\mathrm{Ox} 42$ at both time points, indicating that few newborn cells in the SN are microglia (data not shown).

To investigate the possibility that new neurons are generated in the $\mathrm{SN}$, sections were stained with BrdU and $\beta$-tubulin III or NeuN. In addition, all sections were stained for TH to outline the SN. Hence, we were able to investigate the possibility of generation of new dopaminergic neurons throughout the entire SN. Multiple BrdU-positive nuclei ( $\sim 40$ nuclei per animal) seemed to be associated with $\mathrm{TH}$-positive cell bodies or NeuN-positive nuclei at both time points. However, careful analysis by confocal $z$-series of each of these cells revealed that BrdU-labeled nuclei belonged to cells that were in close proximity to the nuclei of 

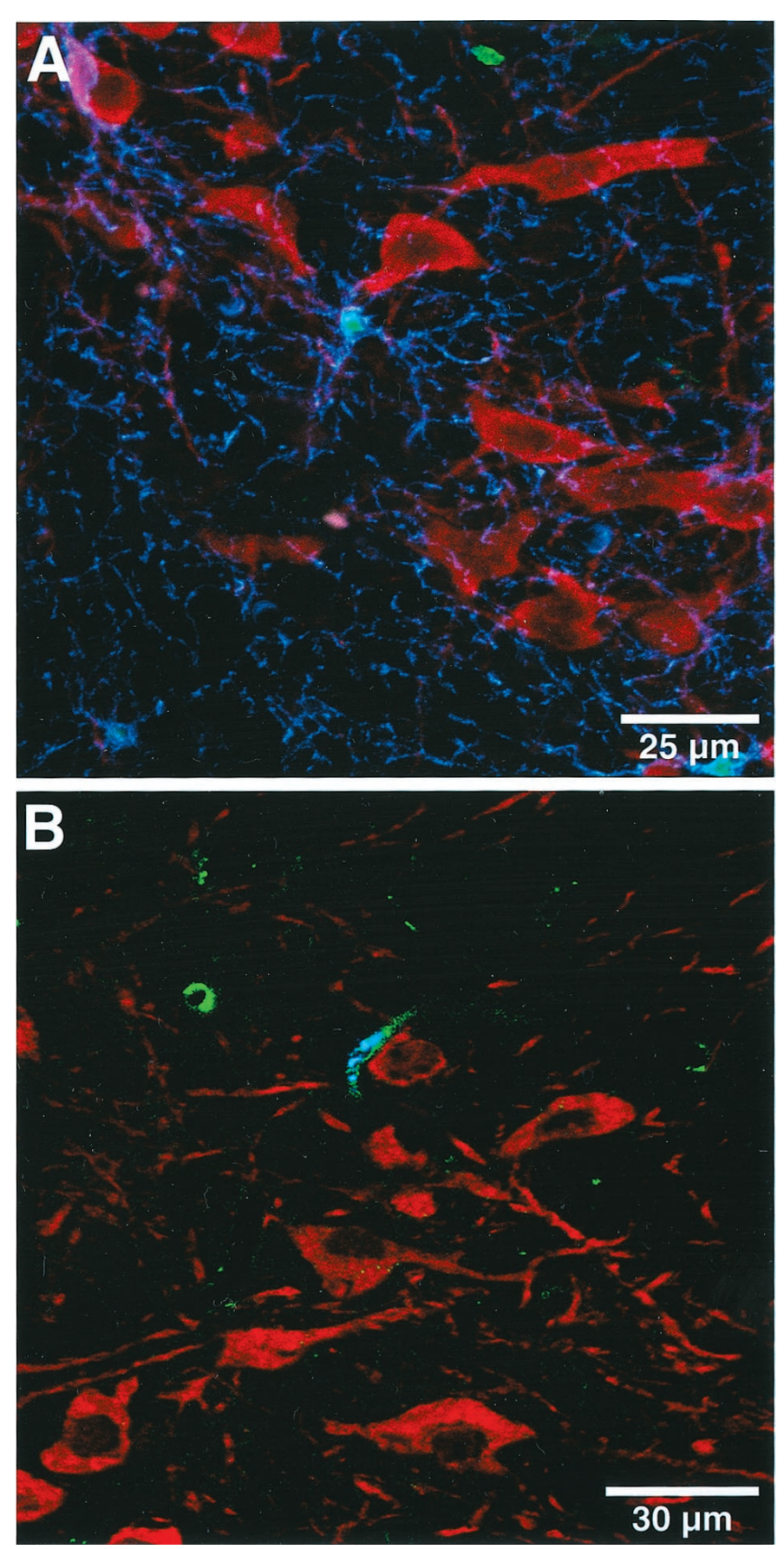

Figure 2. Phenotype of BrdU-positive cells in the SN after a $10 \mathrm{~d}$ BrdU pulse. $A$, One-half of the BrdU-positive cells (green) express the glial progenitor marker NG2 (blue). B, Some BrdU-positive cells (blue) that are not associated with blood vessels express the multipotent progenitor marker nestin (green). $A, B$, TH in shown in red.

NeuN-positive or TH-positive neurons (Fig. 3c). No newly generated neurons were found in animals that were killed at earlier time points ( 1 and 2 weeks after injection), excluding the possibility that progenitor cells had differentiated into neurons that failed to survive (data not shown). In addition, no newborn neurons were observed in adjacent structures in the entire ventral midbrain at any time point. Therefore, no convincing evidence for in vivo neurogenesis in the $\mathrm{SN}$ or the ventral midbrain was found at any of the time points examined.

\section{Isolation of progenitor cells from the SN}

To further characterize the endogenous SN progenitor cell population, we isolated cells from the SN using a protocol that enriches for progenitor cells from the adult brain (Palmer et al., 1999). This procedure allows early in vitro analysis of progenitor cells and avoids prolonged culturing with exposure to high concentrations of growth factors, which can lead to transformation of cells and may dramatically alter their characteristics (Palmer et al., 1997). SN tissue for progenitor cell isolation was harvested by microdissection under a microscope. Although this technique allowed complete removal of the nonadjacent ependymal and subependymal tissue, the possibility remains that the preparation was slightly contaminated with tissue from immediately adjacent tissue (e.g., ventral tegmental area) because of the proximity of structures in the ventral midbrain. To determine whether $\mathrm{SN}$ cells that were actively dividing in vivo were contained in the isolated cell population, animals were injected with high doses of BrdU $(200 \mathrm{mg} / \mathrm{kg})$ on 7 consecutive days before isolation. Cells were fixed $12 \mathrm{hr}$ after isolation and stained for BrdU incorporation. Approximately $6.5 \%$ of the cells were positive for BrdU, indicating that in vivo dividing SN progenitor cells represented a significant proportion of the isolated cells. The percentage of NG2/ BrdU double-labeled cells was similar to that in the in vivo data $(\sim 50 \%)$. No neuronal markers ( $\beta$-tubulin III) and only occasional mature glial markers $(\mathrm{S} 100 \beta)$ were observed among the isolated cells (data not shown).

\section{Lineage potential of SN progenitor cells}

Next we determined the neural lineage potential of SN progenitor cells. Isolated progenitor cells were cultured in the presence of either FGF2, which has been described as a necessary mitogen for maintaining multipotent progenitor cells in vitro (Richards et al., 1992; Vescovi et al., 1993; Palmer et al., 1995; Shihabuddin et al., 1997), or FGF8, which is a mitogen for progenitor cells in the developing midbrain (Lee et al., 1997). To determine whether these two growth factors were able to stimulate the proliferation of progenitor cells, BrdU was added at $5 \mathrm{~d}$ in vitro (DIV) to determine the percentage of dividing cells. At $7 \mathrm{DIV},>90 \%$ of the FGF-treated cells had incorporated BrdU, whereas $<10 \%$ of the cells in control cultures that were grown without the addition of growth factors were BrdU-positive. In addition, control cultures displayed signs of increased cell death, such as fragmented cell nuclei (data not shown). Growth rates of FGF2- and FGF8treated cultures were comparable (data not shown). This demonstrates that FGF2, as well as FGF8, can stimulate the proliferation of SN progenitor cells.

The neural lineage potential of SN-derived progenitors was evaluated by culturing isolated cells in medium containing FGF2 or FGF8 for $7 \mathrm{~d}$. Cells were then fixed and stained for expression of lineage-associated markers. At this time point, cells in both cultures abundantly expressed markers for immature precursors such as nestin, a marker for immature neuroepithelial precursors, and the glial precursor marker NG2 (Table 1). Moreover, low percentages of GFAP-positive astrocytes and $\beta$-tubulin IIIpositive neurons were observed in both culture conditions (Table 1). No RIP-positive oligodendrocytes were detected in the cultures. After retinoic acid-induced differentiation for $7 \mathrm{~d}$ (Takahashi et al., 1999), FGF2- and FGF8-treated cultures contained a significantly higher number of cells that had differentiated into neurons (17\% in FGF2-stimulated cultures; $18 \%$ in FGF8stimulated cultures), astrocytes (6\% and $17 \%$, respectively) and oligodendrocytes ( $2 \%$ in both conditions) (Table 1) (Fig. 4a,b). 

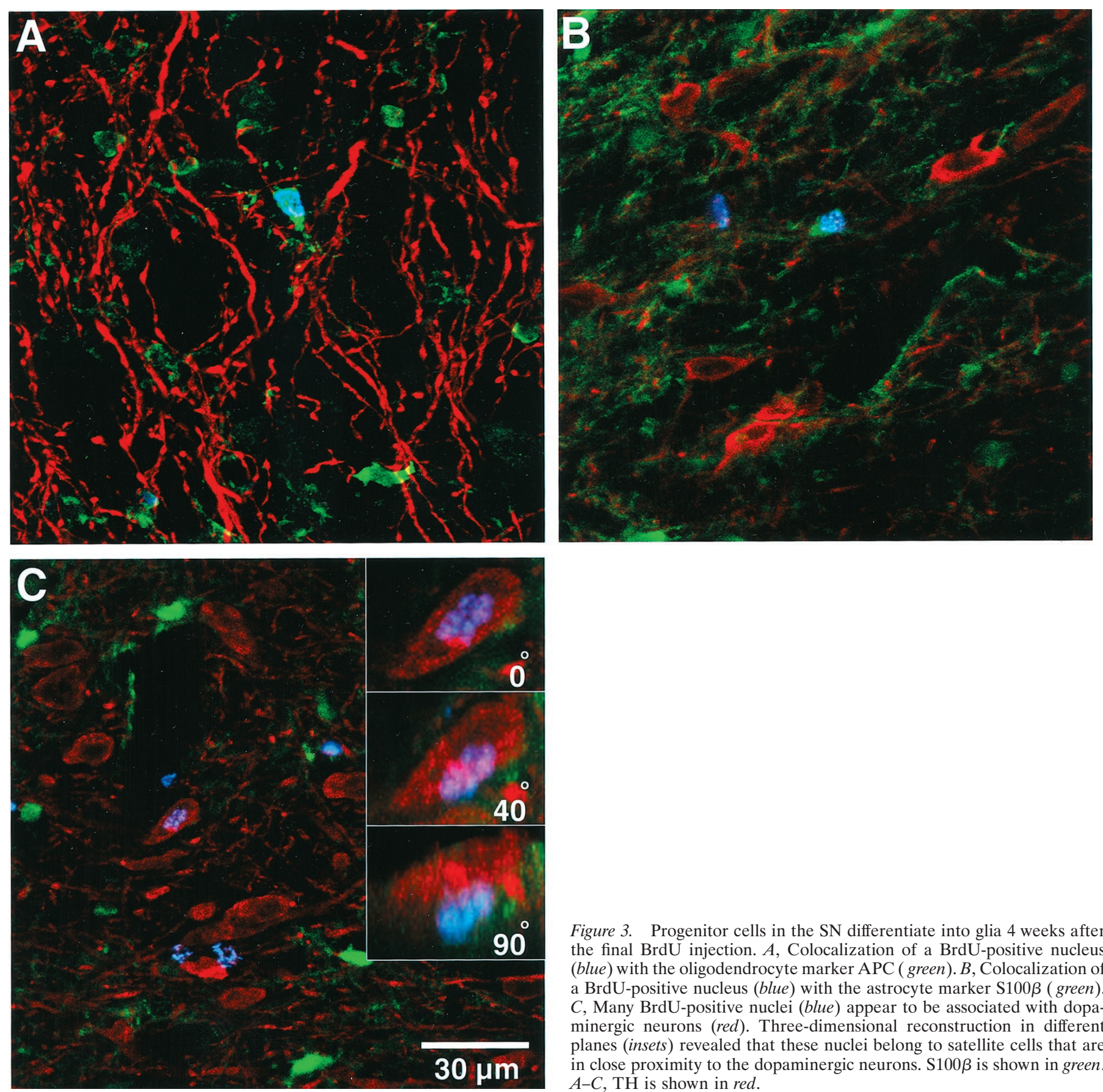

Figure 3. Progenitor cells in the SN differentiate into glia 4 weeks after the final BrdU injection. $A$, Colocalization of a BrdU-positive nucleus (blue) with the oligodendrocyte marker APC ( green). $B$, Colocalization of a BrdU-positive nucleus (blue) with the astrocyte marker $\mathrm{S} 100 \beta$ ( green). $C$, Many BrdU-positive nuclei (blue) appear to be associated with dopaminergic neurons $(r e d)$. Three-dimensional reconstruction in different planes (insets) revealed that these nuclei belong to satellite cells that are in close proximity to the dopaminergic neurons. $\mathrm{S} 100 \beta$ is shown in green. $A-C, \mathrm{TH}$ is shown in red.

Table 1. Expression of glial and neuronal markers by SN progenitor cells under proliferating conditions and after differentiation

\begin{tabular}{|c|c|c|c|c|c|c|}
\hline & Nestin & A2B5 & NG2 & GFAP & RIP & $\beta$-tubulin III \\
\hline FGF2 proliferation & $82.5 \pm 5.7 \%$ & $12.1 \pm 1.9 \%$ & $11.36 \pm 2.0 \%$ & $0.5 \pm 1.8 \%$ & $0 \%$ & $4.3 \pm 1.8 \%$ \\
\hline FGF8 proliferation & $77.2 \pm 9.3 \%$ & $1.5 \pm 0.5 \%$ & $16.02 \pm 1.7 \%$ & $0.4 \pm 0.1 \%$ & $0 \%$ & $2.9 \pm 1.3 \%$ \\
\hline FGF2 differentiation & $25.2 \pm 5.3 \%$ & $0.1 \%$ & $3.1 \pm 0.4 \%$ & $5.9 \pm 1.6 \%$ & $2.2 \pm 1.1 \%$ & $17.1 \pm 1.6 \%$ \\
\hline FGF8 differentiation & $22.9 \pm 3.8 \%$ & $0.8 \pm 0.5 \%$ & $2.7 \pm 0.8 \%$ & $16.6 \pm 2.6 \%$ & $1.9 \pm 0.6 \%$ & $17.9 \pm 3.4 \%$ \\
\hline
\end{tabular}

SN-derived progenitor cells were propagated in the presence of FGF2 or FGF8 for $7 \mathrm{~d}$ and then differentiated in the presence of retinoic acid and FBS for $7 \mathrm{~d}$. Lineage analysis was performed by immunofluorescent staining for lineage-associated markers: nestin (multipotent progenitors), A2B5 and NG2 (glial progenitor cells), GFAP (astrocytes), RIP (oligodendrocytes), and $\beta$-tubulin III (neurons). 

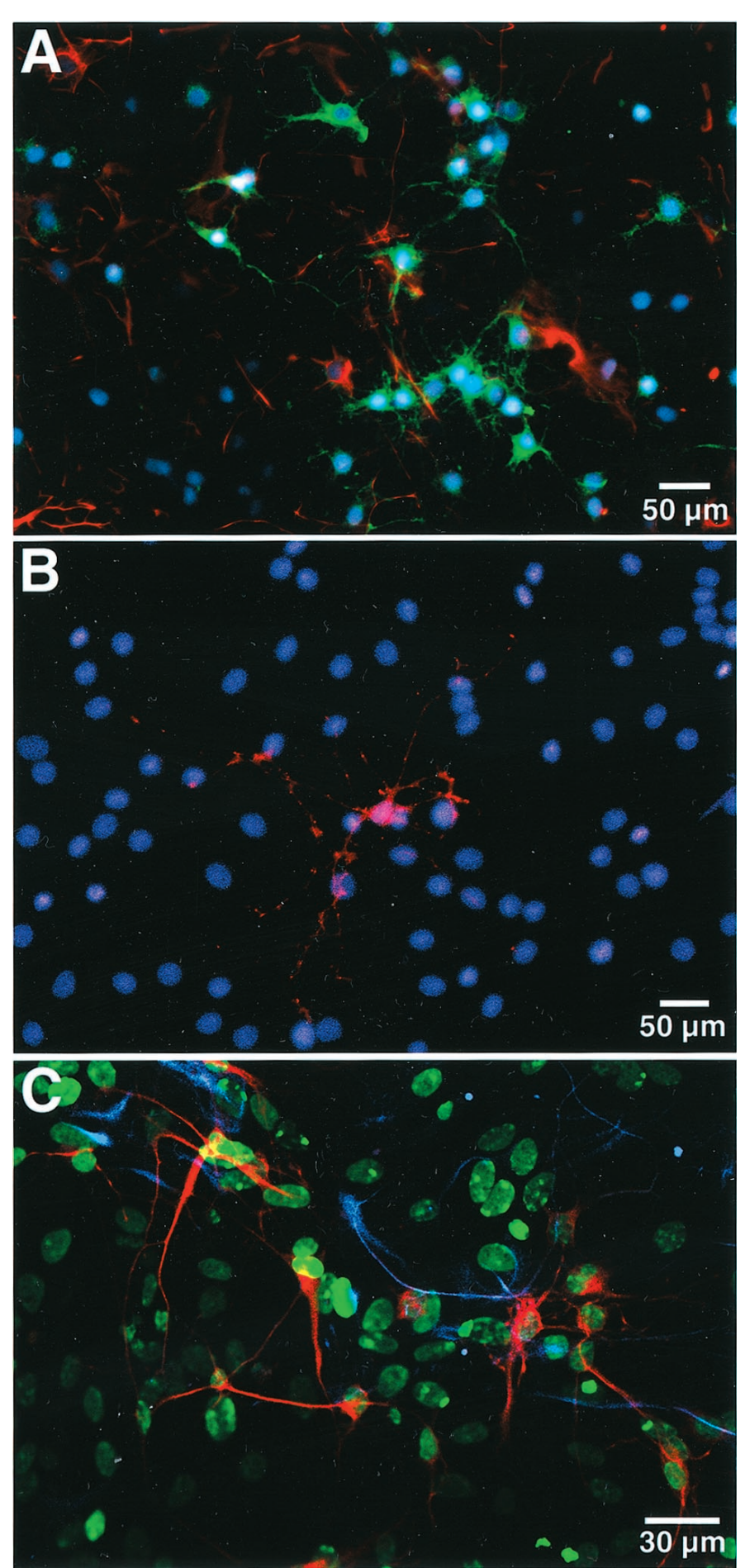

Figure 4. Cultured SN progenitor cells give rise to all three neural lineages in vitro. $\beta$-tubulin III positive-neurons $(A$; green $)$, GFAP-positive astrocytes $(A ;$ red $)$, and RIP-positive oligodendrocytes $(B$; red $)$ are observed after differentiation. $A, B$, Nuclei stained with DAPI (blue). $C$, BrdU was added $48 \mathrm{hr}$ before differentiation. The nuclei of $\beta$-tubulin III-positive neurons (red) and GFAP-positive glia (blue) stain positive for BrdU (green), demonstrating that these cells are derived from a proliferating population.

Cultures were also treated with BrdU for 48 hr before differentiation. After differentiation, the majority $(>85 \%)$ of the neurons and glia were labeled for BrdU, demonstrating that these cells were generated de novo from a dividing cell population (Fig. 4c).
Together, these results demonstrate that SN-derived progenitor cells are able to generate cells from all three neural lineages.

Next, we determined whether SN-derived progenitor cells are multipotent or restricted to a single neural lineage using a previously described clonal analysis approach (Palmer et al., 1999). In brief, proliferating cells were infected with low-titer GFP retroviruses; single GFP-positive cells and their progeny were closely monitored during an initial $7 \mathrm{~d}$ proliferation phase and subsequent $7 \mathrm{~d}$ differentiation phase. Clones were then evaluated for differentiation into neurons and glia. Some clones generated only cells of a single neural lineage (Table 2). However, a significant proportion of clones in both culture conditions contained both neurons and glia (Fig. 5 and Table 2), demonstrating that multipotent progenitor cells are present in these cultures. In addition, these results confirm that neurons and glia are de novo generated from proliferating cells.

We subsequently determined whether the neuronal potential of progenitor cells is confined to quiescent progenitor cells from the $\mathrm{SN}$ or is also a property of actively dividing cells in this region. Animals were injected with BrdU (200 mg/kg) on 7 consecutive days before isolation. Cells were isolated and immediately differentiated for $7 \mathrm{~d}$ using different paradigms. In all conditions, $\sim 1-2 \%$ of the BrdU-positive cells were labeled for the neuronal marker $\beta$-tubulin III (Fig. 6), demonstrating that at least a proportion of actively in vivo dividing cells or their progeny have an intrinsic potential to differentiate into neurons when removed from their in vivo environment.

\section{In vivo neuronal differentiation potential of SN progenitor cells}

Because the possibility remains that $\mathrm{SN}$ progenitor cells can only differentiate into neurons under in vitro conditions and that their potential in vivo is much more restricted, we subsequently determined whether SN progenitor cells can differentiate into neurons in vivo. The adult hippocampus has been demonstrated to provide signals that can direct multipotent cells from different CNS regions toward a neuronal fate (Suhonen et al., 1996; Shihabuddin et al., 2000). We took advantage of this property of the hippocampus to determine whether SN-derived progenitor cells have the potential to differentiate into neurons in vivo. Progenitor cells were freshly isolated and cultured in FGF2 or FGF8 for $6 \mathrm{~d}$. This brief in vitro period removed dying cells from the progenitor cell preparation and allowed the expansion of SN progenitor cells to a sufficient number for the transplantation experiment. Proliferating progenitor cells were labeled with BrdU 2 d before transplantation. Cells were stereotactically injected into the hilar region of the hippocampus. Animals were analyzed 3 weeks later. The distribution of the grafted cells was similar for FGF2- and FGF8-treated cells. The majority of the grafted cells was found close to the grafting site in the hilus or the neuronal layers of the dentate gyrus. However, BrdU-positive cells were observed up to $1.5 \mathrm{~mm}$ along the AP axis and 2.5-3 mm along the ML axis, indicating limited migration of grafted cells. Approximately $20 \%$ of grafted cells ( $\sim 160$ cells of a total of 800 grafted cells examined) in the neuronal layers of the dentate gyrus expressed early and/or mature neuronal markers such as $\beta$-tubulin III and NeuN (Fig. $7 a$ and Table 3). These cells were not only located in the subgranular zone but also appeared to be integrated into deeper layers of the granular cell layer. These results demonstrate that SN-derived progenitor cells have the potential to differentiate into neurons not only in vitro but also in vivo when provided with an appropriate environment. 
Table 2. Phenotypic characterization of differentiated clonal SN progenitor cells propagated in the presence of FGF2 or FGF8

\begin{tabular}{|c|c|c|c|c|}
\hline & Neurons only & Glia only & Bipotent & No markers \\
\hline FGF2 & $24.7 \%$ & $4.7 \%$ & $4.7 \%$ & $65.9 \%$ \\
\hline FGF8 & $40 \%$ & $13.3 \%$ & $11.1 \%$ & $35.6 \%$ \\
\hline
\end{tabular}

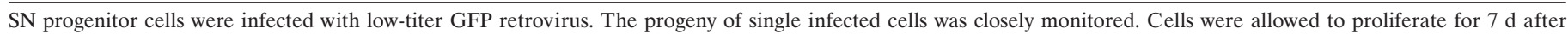

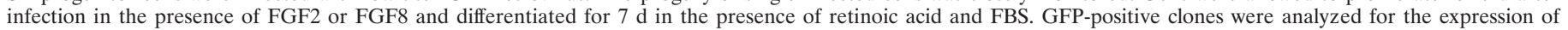

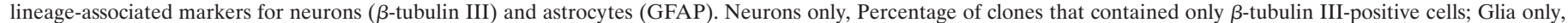

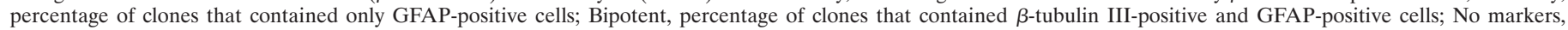
percentage of clones that were negative for glial and neuronal markers.

Progenitor cells were also grafted into the adult SN. Grafted cells were observed up to $1 \mathrm{~mm}$ along the AP axis and $1.2 \mathrm{~mm}$ along the ML axis. Sections were stained for BrdU and markers for the neuronal lineage to establish whether grafted cells were able to adopt a neuronal phenotype in the SN. However, in contrast to their hippocampus-grafted counterparts, neither FGF2- nor FGF8-stimulated progenitor cells gave rise to any $\beta$-tubulin III-, NeuN-, or TH-positive neurons. Instead, we found that $\sim 30 \%$ of the grafted cells ( $\sim 240$ cells of a total of 800 cells examined) showed a glial progenitor phenotype by expressing the marker NG2 (Fig. 7b). These results highlight the role of the environment for differentiation of SN-derived progenitor cells into neurons in vivo.

\section{Dopaminergic neurogenesis in the $\mathrm{SN}$ is not induced by 6-OHDA lesion}

Because dividing cells or their progeny from the adult SN can give rise to neurons in vitro and in vivo after transplantation, we hypothesized that cell death of dopaminergic neurons in the SN can induce de novo neurogenesis in this region. Previous studies had shown that mechanisms regulating neuronal migration, differentiation, and connectivity during development are reactivated after lesion of the adult brain (Wang et al., 1998; Leavitt et al., 1999), and that limited neurogenesis occurs after specific lesions in the adult neocortex (Magavi et al., 2000). Animals were injected with 6-OHDA into the left medial forebrain bundle, which leads to a selective loss of dopaminergic neurons in the SN. Dividing cells were labeled by daily injections of BrdU for 12 consecutive days. The exact number of BrdU-positive cells within the lesioned SN could not be determined because of the absence of dopaminergic neurons that were used previously to anatomically demarcate the SN. Nevertheless, there was an apparent increase in the number of BrdU cells in the lesioned SN compared with the unlesioned control side. All sections were screened for newly generated neurons by costaining of BrdU with neuronal markers (NeuN, $\beta$-tubulin III) and a dopaminergic marker (TH). None of the newly generated cells colabeled for any of these markers. These findings suggest that dopaminergic cell loss induced by 6-OHDA is not sufficient to induce neurogenesis in the $\mathrm{SN}$.

\section{DISCUSSION}

Fetal neural progenitor cells have been isolated repeatedly from the mesencephalon and have been used in experimental cellreplacement approaches for PD (Ling et al., 1998; Studer et al., 1998; Potter et al., 1999; Studer et al., 2000; Sanchez-Pernaute et al., 2001; Sawamoto et al., 2001). Although previous work has suggested that neural progenitor cells persist throughout adulthood in diverse areas of the CNS (Gage et al., 1995; Palmer et al., 1995; Weiss et al., 1996; Shihabuddin et al., 1997; Palmer et al.,
1999), there has been little evidence for the existence of progenitor cells in the adult SN.

In the present study, we have shown the presence of actively dividing cells in the SN that are able to give rise to oligodendrocytes and astrocytes in vivo. These newly generated glial cells were not observed immediately after the BrdU pulse but only 4 weeks after the final BrdU injection. This delay suggests that these cells are derived from more immature progenitor cells that have differentiated into mature glial cells and not from dividing mature glia. Almost 50\% of the BrdU-labeled cells were associated with the glial progenitor marker NG2 (Levine and Stallcup, 1987; Keirstead et al., 1998; Horner et al., 2000) immediately after the BrdU pulse, and the percentage of NG2/BrdU-labeled cells tended to decrease over time. It is therefore possible that the newly generated glial cells in the SN are the progeny of NG2positive progenitors. In this regard, the adult $\mathrm{SN}$ displays characteristics that are different from the adult cortex, where NG2 cells constitute only a minor proportion of dividing cells (Mehler and Gokhan, 1999; Gensert and Goldman, 2001), but resembles the adult spinal cord (Horner et al., 2000), where NG2-positive progenitor cells are the major dividing cell population and mature glial cells are generated from immature dividing cells.

The phenotype of the remaining proliferating cells remains unclear. Endothelial cells proliferate within the CNS (Horner et al., 2000; Palmer et al., 2000), and our preliminary results indicate that indeed some of the BrdU-labeled cells colocalize with endothelial cell markers (data not shown). However, most of the BrdU-positive cells of unknown phenotype were not found in the walls of blood vessels, which suggests a phenotype other than endothelial cells.

The presence of newborn glial cells in the adult SN suggests that constant glial cell replacement is taking place in this region. Previous findings that glial cells are key regulators of synaptic transmission and extracellular homeostasis in the CNS underline the importance of the maintenance of the glial population ( $\mathrm{Pfr}$ ieger and Barres, 1996; Ransom and Orkand, 1996; Lee et al., 2000; Araque et al., 2001). Future experiments need to address the functional relevance of gliogenesis in the $\mathrm{SN}$ for the maintenance of the glial population.

Despite careful cell-by-cell analysis, we have no indication that neurogenesis occurs either in the intact or in the lesioned SN. Multiple BrdU-positive nuclei were closely associated with dopaminergic neurons. However, detailed analysis of these nuclei (a total of $\sim 800$ cells) by three-dimensional confocal analysis clearly demonstrated that these nuclei without exception belonged to cells that were closely attached to the dopaminergic neurons. The proximity of newborn cells with mature existing neurons has been observed in different areas of the adult CNS (Kuhn et al., 1997; Kornack and Rakic, 2001). The significance of this phenomenon is not known; however, one could speculate that this close asso- 

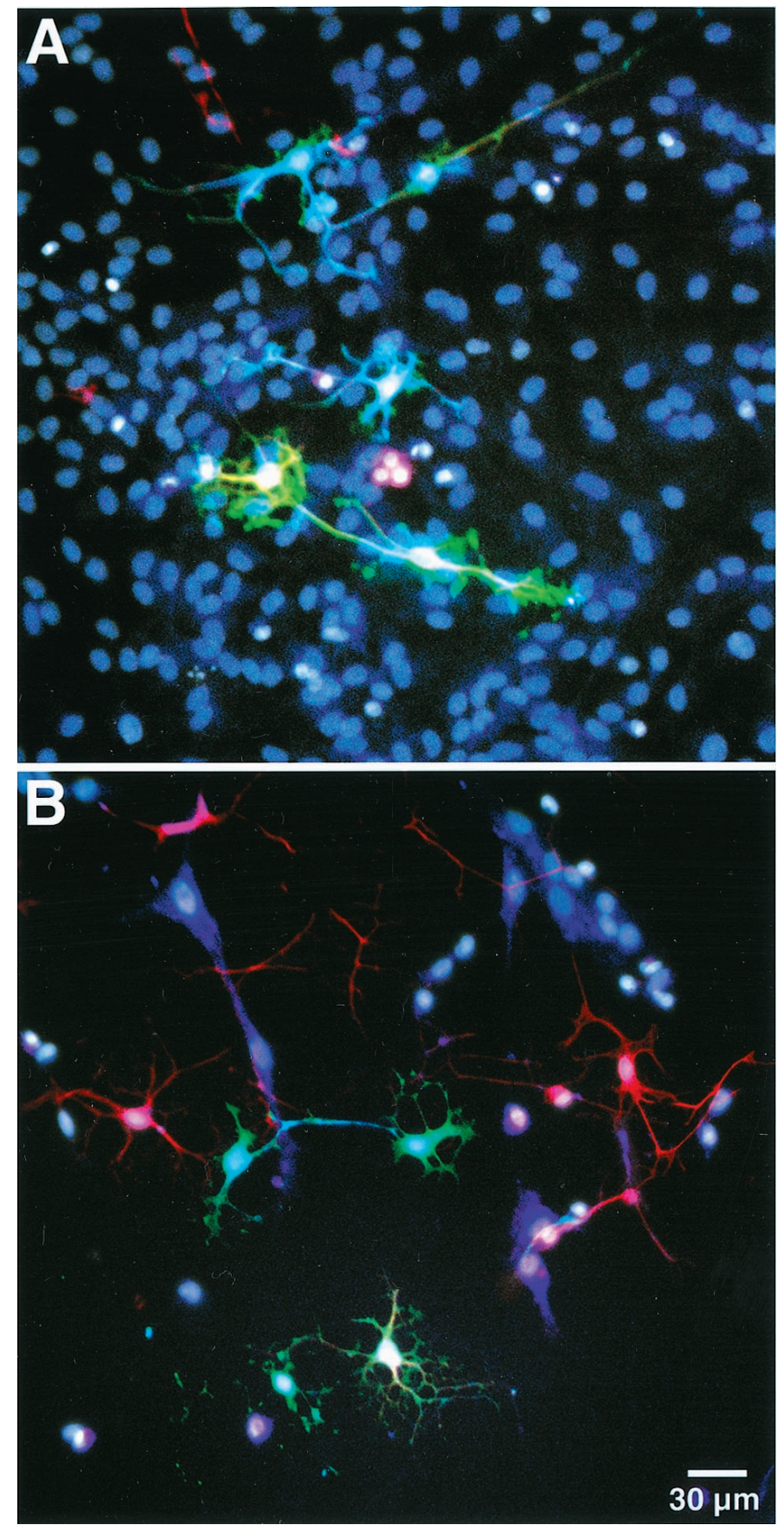

Figure 5. Lineage potential of individual SN progenitor cells. Cells were infected with low-titer GFP retrovirus. Individual infected cells and their progeny were differentiated after a $7 \mathrm{~d}$ proliferation period in FGF8supplemented media $(A)$ or FGF2-supplemented media $(B)$. After differentiation, some GFP-positive clones ( green) produced $\beta$-tubulin IIIpositive neurons (red; seen as orange with GFP overlay) and GFAPpositive astrocytes (blue; seen as aqua with GFP overlay), demonstrating that the infected progenitor cell was multipotent. Nuclei stained with DAPI are dark blue.

ciation is necessary for cross talk between those cells, for induction of differentiation, or for trophic support. Our failure to detect neurogenesis in the $\mathrm{SN}$ is consistent with a previous study in which cell proliferation but no generation of new neurons after 1-methyl-4-phenyl-1,2,3,6-tetrahydropyridine lesion was observed (Kay and Blum, 2000). We cannot rule out the possibility that

\section{$\Delta$}

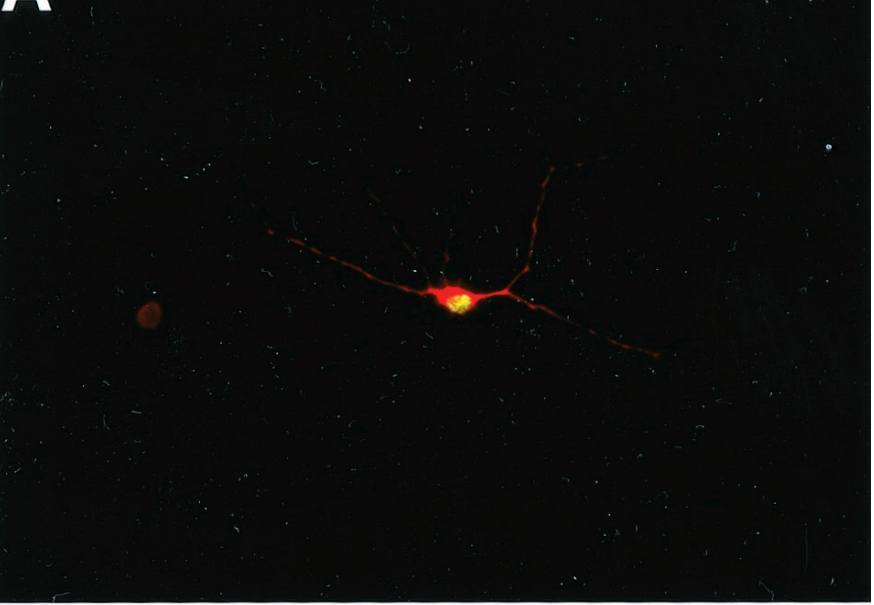

\section{B)}

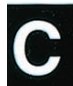

$20 \mu \mathrm{m}$

Figure 6. In vivo proliferating $\mathrm{SN}$ progenitor cells have an intrinsic neuronal potential. Proliferating progenitor cells were labeled in vivo by injection of BrdU. SN progenitor cells were differentiated immediately after isolation. $\beta$-tubulin III-positive neurons (red) with BrdU-positive nuclei (green) were observed in all differentiation conditions tested: astrocyte feeder layer $(A)$, forskolin-induced differentiation $(B)$, and retinoic acid-induced differentiation $(C)$. 

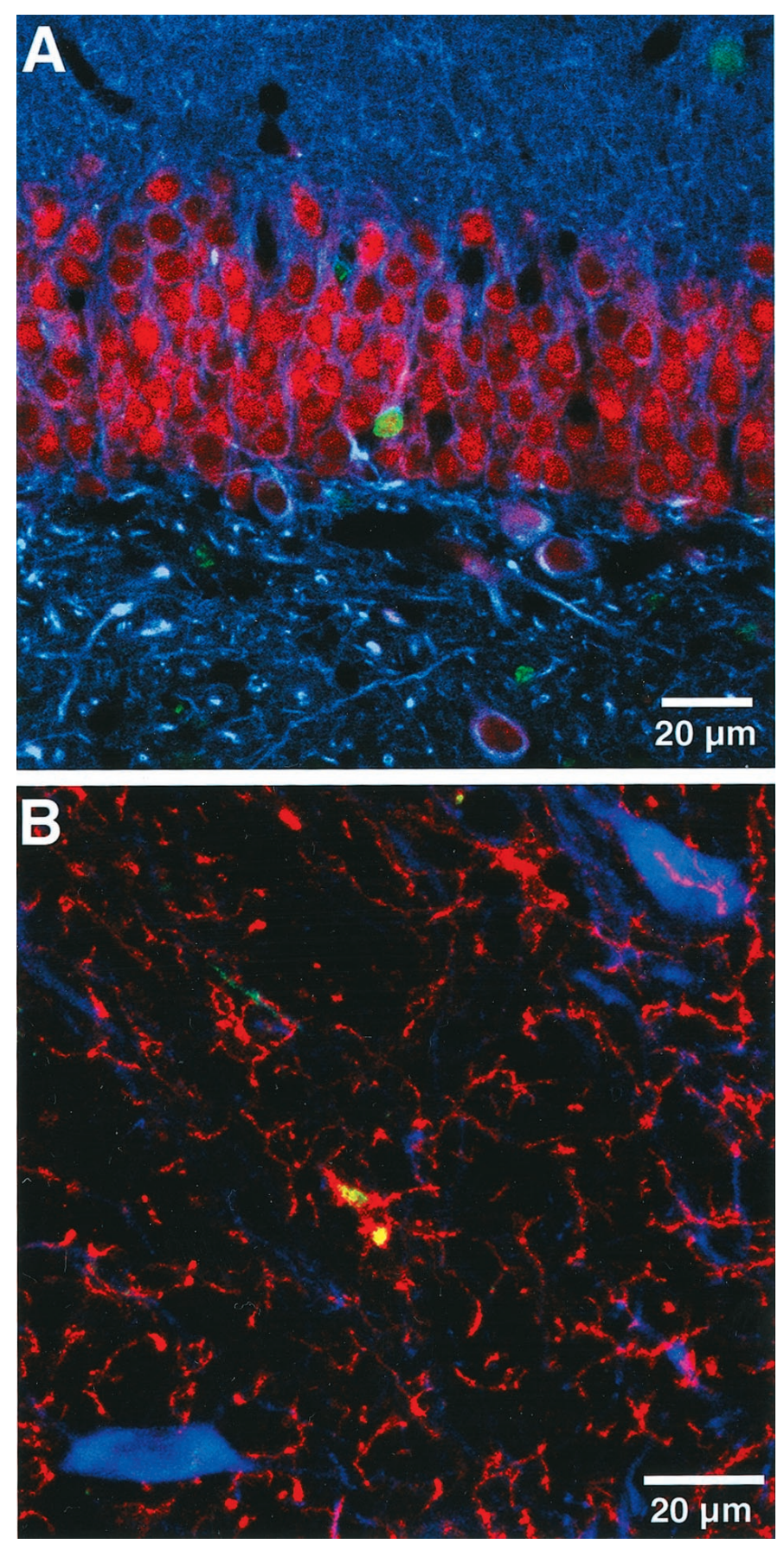

Figure 7. In vivo neuronal differentiation potential of SN progenitor cells. $A$, BrdU-labeled SN progenitor cells ( green) differentiate into NeuN (red)/ $\beta$-tubulin III (blue)-positive neurons after transplantation to the hippocampus, demonstrating that $\mathrm{SN}$ progenitor cells can differentiate into neurons in vivo. $B$, In contrast, SN progenitor cells transplanted back to the SN do not differentiate into neurons, but display an NG2-positive glial progenitor phenotype (red), suggesting that the SN environment is not permissive for neuronal differentiation. BrdU is shown in green; $\mathrm{TH}$ is shown in blue.

neurogenesis in the $\mathrm{SN}$ is an extremely low-frequency event that escapes detection by our BrdU-injection paradigm. However, in our paradigm we used BrdU at a concentration in the range of a dose that allowed the detection of a large pool of proliferating cells and their progeny in the adult hippocampus (Cameron and
Table 3. Expression of neuronal markers by SN progenitor cells transplanted into the adult hippocampal dentate gyrus after $6 \mathrm{~d}$ of expansion in FGF2 or FGF8

\begin{tabular}{lllll} 
& $\begin{array}{l}\text { Neuronal } \\
\text { markers }\end{array}$ & $\beta$-tubulin III & NeuN & $\begin{array}{l}\beta \text {-tubulin } \\
\text { III/NeuN }\end{array}$ \\
\hline FGF2 & $19.4 \pm 2.8 \%$ & $5.0 \pm 1.1 \%$ & $16.2 \pm 2.7 \%$ & $1.8 \pm 0.9 \%$ \\
FGF8 & $20.9 \pm 4.4 \%$ & $8.2 \pm 2.9 \%$ & $18.5 \pm 3.4 \%$ & $5.8 \pm 1.9 \%$ \\
\hline
\end{tabular}

Relative expression of neuronal markers by transplanted SN progenitor cells in the adult dentate gyrus 3 weeks after transplantation. SN progenitor cells were cultured $6 \mathrm{~d}$ before transplantation in the presence of FGF2 or FGF8 and labeled with BrdU. Sections were triple-labeled for BrdU and the neuronal markers $\beta$-tubulin III and NeuN.

McKay, 2001), making it unlikely that any newly generated neurons were not labeled with BrdU.

A previously described progenitor cell enrichment protocol (Palmer et al., 1999) enabled us to further characterize SN progenitor cells. In striking contrast to their glial-restricted differentiation pattern in vivo, isolated $\mathrm{SN}$ progenitor cells differentiated into all neural lineages including neurons in vitro. Interestingly, the ability of $\mathrm{SN}$ progenitor cells to differentiate into neurons was observed in progenitor cells that had proliferated previously in vivo. Another important point is that in vivo proliferating SN progenitor cells could differentiate into neurons immediately after isolation, without short-term exposure to high doses of FGF2 which in previous in vitro studies led to neuronal differentiation of glial-restricted precursors (Palmer et al., 1999; Kondo and Raff, 2000). Together, these results suggest that at least a subpopulation of proliferating progenitor cells in the adult $\mathrm{SN}$ have an intrinsic neurogenic potential that is suppressed by the local environment. At this point it is not clear which population of in vivo dividing cells has this potential. Previous studies have proposed that new neurons are derived from multipotent GFAP-positive cells (Doetsch et al., 1999; Laywell et al., 2000) or ependymal cells (Johansson et al., 1999) within neurogenic areas of the adult CNS. However, our dissection approach (tissue adjacent to the ventricle was completely removed) rules out the possibility that ependymal cells were the in vivo proliferating cells that gave rise to neurons in culture immediately after isolation, and we have not found evidence for proliferating GFAP-positive cells in the adult SN. A small subset of in vivo dividing cells expressed nestin, a marker for multipotent neural progenitor cells during development (Lendahl et al., 1990). It is possible that the proliferating nestin-positive cells in the adult SN correspond to the multipotent cells detected in our clonal analysis, and that these cells are giving rise to neurons after isolation. The future identification of definite markers for adult multipotent CNS progenitor cells will be very helpful in clarifying this point. We were also able to demonstrate that the neuronal differentiation potential of SN progenitor cells is not confined to in vitro conditions but extends to the in vivo situation. SN progenitor cells that were transplanted into the adult hippocampus were able to survive at least 3 weeks in this location and expressed markers of both immature and mature neurons. Because grafted cells were labeled with BrdU just before transplantation, these neurons were exclusively derived from proliferating progenitor cells and not from cells that had already differentiated into postmitotic neurons in vitro. Some of the SN progenitor cell-derived neurons were found in deeper layers of the dentate granular cell layer, indicating the possibility that they had integrated into the hippocampal circuit. To investigate this possibility, our future experiments will 
address whether these neurons receive synaptic inputs and make functional connections.

In previous experiments, we have shown that multipotent progenitor cells from different CNS regions generate neurons after transplantation into the adult hippocampus (Suhonen et al., 1996; Shihabuddin et al., 2000). These cells were cultured for $>2$ years before transplantation, increasing the likelihood for transformation and/or alterations of their native characteristics (Palmer et al., 1997). It is important to note that in the present experiments, the transplanted progenitor cells were only cultured for $6 \mathrm{~d}$ and yet were able to differentiate into neurons. This finding indicates that prolonged culture is not a prerequisite for adult progenitor cells from non-neurogenic regions to differentiate into neurons in a heterotopic neurogenic environment. Moreover it adds to the existing evidence that the adult hippocampus provides general proneuronal signals that can be interpreted by adult progenitor cells from CNS regions as different as the hippocampus, spinal cord, and SN.

One striking observation is that, in contrast to their hippocampus-grafted counterparts, progenitor cells derived from either the adult SN (this study) or the adult hippocampus (data not shown) did not differentiate into neurons after transplantation into the SN. These findings strongly emphasize the importance of the environment for neurogenesis and suggest that proneuronal signals are absent and/or that inhibitory signals of neuronal differentiation are present in the adult SN. The presence or absence of these signals also would explain our observation that although progenitor cells differentiate only into glial phenotypes in situ, they are able to differentiate immediately into neurons after removal from the $\mathrm{SN}$ and exposure to proneuronal signals.

Exposure to FGF2 or FGF8 was not required for neuronal differentiation of in vivo proliferating progenitor cells but was necessary for efficient recruitment of SN progenitor cells into the cell cycle and maintenance of these cells in culture. Our preliminary results suggest that neither of the factors is expressed at high levels in the adult SN. It is possible that delivery of FGF2 or FGF8 into the adult SN increases the proliferation of endogenous multipotent progenitor cells, thereby increasing the pool of cells with a neuronal potential. However, the failure of FGF2- or FGF8-treated cells to differentiate into neurons after transplantation into the SN indicates that these two factors are not sufficient to promote in situ neuronal differentiation of SN progenitors. In a recent report, Lim et al. (2000) demonstrated that bone morphogenetic protein-4 (BMP4) inhibits neuronal differentiation of adult multipotent progenitor cells in vivo and promotes glial differentiation. The BMP-antagonist Noggin is highly expressed close to the neurogenic subventricular zone and promotes neuronal differentiation by blocking the gliogenic actions of BMP4. It is possible that this antagonism between BMP4 and Noggin regarding the neural fate of progenitor cells holds true for other CNS regions, including the adult $\mathrm{SN}$, and that lack of Noggin expression is in part responsible for the exclusive glial differentiation of SN progenitor cells in situ.

In summary, we have demonstrated that the adult SN contains neural progenitor cells with the potential to differentiate into neurons. Some of these cells with a neuronal differentiation potential are readily proliferating under physiological conditions, which opens up the possibility that provision of proneuronal differentiation signals might be sufficient to drive these cells down a neuronal lineage. The presence of these cells in the SN might be very useful for endogenous cell-replacement strategies for the treatment of PD, in which SN dopaminergic neurons degenerate. Future experiments need to be directed at the characterization of the microenvironment of the $\mathrm{SN}$ as a first step to generating a permissive environment for neuronal differentiation. In addition, signals need to be identified that can direct the differentiation of adult SN progenitor cells toward a dopaminergic neurotransmitter phenotype.

\section{REFERENCES}

Altman J, Das GD (1965) Autoradiographic and histological evidence of postnatal hippocampal neurogenesis in rats. J Comp Neurol 124:319-335.

Araque A, Carmignoto G, Haydon PG (2001) Dynamic signaling between astrocytes and neurons. Annu Rev Physiol 63:795-813.

Bayer SA (1982) Changes in the total number of dentate granule cells in juvenile and adult rats: a correlated volumetric and ${ }^{3} \mathrm{H}$-thymidine autoradiographic study. Exp Brain Res 46:315-323.

Bjorklund A, Lindvall O (2000) Cell replacement therapies for central nervous system disorders. Nat Neurosci 3:537-544.

Cameron HA, McKay RD (2001) Adult neurogenesis produces a large pool of new granule cells in the dentate gyrus. J Comp Neurol 435:406-417.

Doetsch F, Caille I, Lim DA, Garcia-Verdugo JM, Alvarez-Buylla A (1999) Subventricular zone astrocytes are neural stem cells in the adult mammalian brain. Cell 97:703-716.

Dunnett SB, Bjorklund A, Lindvall O (2001) Cell therapy in Parkinson's disease - stop or go? Nat Rev Neurosci 2:365-369.

Freed CR, Greene PE, Breeze RE, Tsai WY, DuMouchel W, Kao R, Dillon S, Winfield H, Culver S, Trojanowski JQ, Eidelberg D, Fahn S (2001) Transplantation of embryonic dopamine neurons for severe Parkinson's disease. N Engl J Med 344:710-719.

Gage FH, Coates PW, Palmer TD, Kuhn HG, Fisher LJ, Suhonen JO, Peterson DA, Suhr ST, Ray J (1995) Survival and differentiation of adult neuronal progenitor cells transplanted to the adult brain. Proc Natl Acad Sci USA 92:11879-11883.

Gensert JM, Goldman JE (2001) Heterogeneity of cycling glial progenitors in the adult mammalian cortex and white matter. J Neurobiol 48:75-86.

Horner PJ, Power AE, Kempermann G, Kuhn HG, Palmer TD, Winkler J, Thal LJ, Gage FH (2000) Proliferation and differentiation of progenitor cells throughout the intact adult rat spinal cord. J Neurosci 20:2218-2228.

Johansson CB, Momma S, Clarke DL, Risling M, Lendahl U, Frisen J (1999) Identification of a neural stem cell in the adult mammalian central nervous system. Cell 96:25-34.

Kaplan MS, Bell DH (1984) Mitotic neuroblasts in the 9-day-old and 11-month-old rodent hippocampus. J Neurosci 4:1429-1441.

Kay JN, Blum M (2000) Differential response of ventral midbrain and striatal progenitor cells to lesions of the nigrostriatal dopaminergic projection. Dev Neurosci 22:56-67.

Keirstead HS, Levine JM, Blakemore WF (1998) Response of the oligodendrocyte progenitor cell population (defined by NG2 labelling) to demyelination of the adult spinal cord. Glia 22:161-170.

Kobayashi M, Sjoberg G, Soderhall S, Lendahl U, Sandstedt B, Sejersen $T$ (1998) Pediatric rhabdomyosarcomas express the intermediate filament nestin. Pediatr Res 43:386-392.

Kondo T, Raff M (2000) Oligodendrocyte precursor cells reprogrammed to become multipotential CNS stem cells. Science 289:1754-1757.

Kornack DR, Rakic P (2001) Cell proliferation without neurogenesis in adult primate neocortex. Science 294:2127-2130.

Kuhn HG, Dickinson-Anson H, Gage FH (1996) Neurogenesis in the dentate gyrus of the adult rat: age-related decrease of neuronal progenitor proliferation. J Neurosci 16:2027-2033.

Kuhn HG, Winkler J, Kempermann G, Thal LJ, Gage FH (1997) Epidermal growth factor and fibroblast growth factor-2 have different effects on neural progenitors in the adult rat brain. $J$ Neurosci 17:5820-5829.

Laywell ED, Rakic P, Kukekov VG, Holland EC, Steindler DA (2000) Identification of a multipotent astrocytic stem cell in the immature and adult mouse brain. Proc Natl Acad Sci USA 97:13883-13888.

Leavitt BR, Hernit-Grant CS, Macklis JD (1999) Mature astrocytes transform into transitional radial glia within adult mouse neocortex that supports directed migration of transplanted immature neurons. Exp Neurol 157:43-57.

Lee JC, Mayer-Proschel M, Rao MS (2000) Gliogenesis in the central nervous system. Glia 30:105-121.

Lee SM, Danielian PS, Fritzsch B, McMahon AP (1997) Evidence that FGF8 signalling from the midbrain-hindbrain junction regulates growth and polarity in the developing midbrain. Development 124:959-969.

Lendahl U, Zimmerman LB, McKay RD (1990) CNS stem cells express a new class of intermediate filament protein. Cell 60:585-595. 
Levine JM, Stallcup WB (1987) Plasticity of developing cerebellar cells in vitro studied with antibodies against the NG2 antigen. J Neurosci 7:2721-2731.

Levison SW, Goldman JE (1993) Both oligodendrocytes and astrocytes develop from progenitors in the subventricular zone of postnatal rat forebrain. Neuron 10:201-212.

Lim DA, Tramontin AD, Trevejo JM, Herrera DG, Garcia-Verdugo JM, Alvarez-Buylla A (2000) Noggin antagonizes BMP signaling to create a niche for adult neurogenesis. Neuron 28:713-726.

Lindvall O, Hagell P (2000) Clinical observations after neural transplantation in Parkinson's disease. Prog Brain Res 127:299-320.

Ling ZD, Potter ED, Lipton JW, Carvey PM (1998) Differentiation of mesencephalic progenitor cells into dopaminergic neurons by cytokines. Exp Neurol 149:411-423.

Lois C, Alvarez-Buylla A (1993) Proliferating subventricular zone cells in the adult mammalian forebrain can differentiate into neurons and glia. Proc Natl Acad Sci USA 90:2074-2077.

Luskin MB (1993) Restricted proliferation and migration of postnatally generated neurons derived from the forebrain subventricular zone. Neuron 11:173-189.

Magavi SS, Leavitt BR, Macklis JD (2000) Induction of neurogenesis in the neocortex of adult mice. Nature 405:951-955.

Mehler MF, Gokhan S (1999) Postnatal cerebral cortical multipotent progenitors: regulatory mechanisms and potential role in the development of novel neural regenerative strategies. Brain Pathol 9:515-526.

Olanow CW, Kordower JH, Freeman TB (1996) Fetal nigral transplantation as a therapy for Parkinson's disease. Trends Neurosci 19:102-109.

Olanow CW, Watts RL, Koller WC (2001) An algorithm (decision tree) for the management of Parkinson's disease (2001): treatment guidelines. Neurology 56:S1-S88.

Palmer TD, Ray J, Gage FH (1995) FGF-2-responsive neuronal progenitors reside in proliferative and quiescent regions of the adult rodent brain. Mol Cell Neurosci 6:474-486.

Palmer TD, Takahashi J, Gage FH (1997) The adult rat hippocampus contains primordial neural stem cells. Mol Cell Neurosci 8:389-404.

Palmer TD, Markakis EA, Willhoite AR, Safar F, Gage FH (1999) Fibroblast growth factor-2 activates a latent neurogenic program in neural stem cells from diverse regions of the adult CNS. J Neurosci 19:8487-8497.

Palmer TD, Willhoite AR, Gage FH (2000) Vascular niche for adult hippocampal neurogenesis. J Comp Neurol 425:479-494.

Pfrieger FW, Barres BA (1996) New views on synapse-glia interactions. Curr Opin Neurobiol 6:615-621.

Potter ED, Ling ZD, Carvey PM (1999) Cytokine-induced conversion of mesencephalic-derived progenitor cells into dopamine neurons. Cell Tissue Res 296:235-246.
Ransom BR, Orkand RK (1996) Glial-neuronal interactions in nonsynaptic areas of the brain: studies in the optic nerve. Trends Neurosci 19:352-358.

Richards LJ, Kilpatrick TJ, Bartlett PF (1992) De novo generation of neuronal cells from the adult mouse brain. Proc Natl Acad Sci USA 89:8591-8595.

Sanchez-Pernaute R, Studer L, Bankiewicz KS, Major EO, McKay RD (2001) In vitro generation and transplantation of precursor-derived human dopamine neurons. J Neurosci Res 65:284-288.

Sawamoto K, Nakao N, Kakishita K, Ogawa Y, Toyama Y, Yamamoto A, Yamaguchi M, Mori K, Goldman SA, Itakura T, Okano H (2001) Generation of dopaminergic neurons in the adult brain from mesencephalic precursor cells labeled with a nestin-GFP transgene. J Neurosci 21:3895-3903.

Shihabuddin LS, Ray J, Gage FH (1997) FGF-2 is sufficient to isolate progenitors found in the adult mammalian spinal cord. Exp Neurol 148:577-586.

Shihabuddin LS, Horner PJ, Ray J, Gage FH (2000) Adult spinal cord stem cells generate neurons after transplantation in the adult dentate gyrus. J Neurosci 20:8727-8735.

Song H, Stevens CF, Gage FH (2002) Astroglia induce neurogenesis from adult neural stem cells. Nature 417:39-44.

Studer L, Tabar V, McKay RD (1998) Transplantation of expanded mesencephalic precursors leads to recovery in parkinsonian rats. Nat Neurosci 1:290-295.

Studer L, Csete M, Lee SH, Kabbani N, Walikonis J, Wold B, McKay R (2000) Enhanced proliferation, survival, and dopaminergic differentiation of CNS precursors in lowered oxygen. J Neurosci 20:7377-7383.

Suhonen JO, Peterson DA, Ray J, Gage FH (1996) Differentiation of adult hippocampus-derived progenitors into olfactory neurons in vivo. Nature 383:624-627.

Takahashi J, Palmer TD, Gage FH (1999) Retinoic acid and neurotrophins collaborate to regulate neurogenesis in adult-derived neural stem cell cultures. J Neurobiol 38:65-81.

Vescovi AL, Reynolds BA. Fraser DD, Weiss S (1993) bFGF regulates the proliferative fate of unipotent (neuronal) and bipotent (neuronal/ astroglial) EGF-generated CNS progenitor cells. Neuron 11:951-966.

Wang Y, Sheen VL, Macklis JD (1998) Cortical interneurons upregulate neurotrophins in vivo in response to targeted apoptotic degeneration of neighboring pyramidal neurons. Exp Neurol 154:389-402.

Weiss S, Dunne C, Hewson J, Wohl C, Wheatley M, Peterson AC, Reynolds BA (1996) Multipotent CNS stem cells are present in the adult mammalian spinal cord and ventricular neuroaxis. J Neurosci 16:7599-7609.

West MJ (1999) Stereological methods for estimating the total number of neurons and synapses: issues of precision and bias. Trends Neurosci 22:51-61. 